\title{
An Investigation of Corrosion Progression Using Laser Profilometry
}

\author{
Hong ZHANG ${ }^{\mathrm{a}, 1}$ and Ruikun $\mathrm{WU}^{\mathrm{b}}$ \\ ${ }^{a}$ Key Laboratory of Nondestructive Testing, Fuqing Branch of Fujian Normal University, Fuqing, P. R. \\ China \\ ${ }^{\mathrm{b}}$ School of Electronic and Information Engineering, Fuqing Branch of Fujian Normal University, Fuqing, P. \\ R. China
}

\begin{abstract}
Atmospheric corrosion progression characterisation on metal substrates is a major problem in the field of corrosion science and Non-destructive Evaluation (NDE). A laser profilometry has been used to characterise the corrosion on the mild steel plate at a low cost and high resolution. Four mild steel samples have been measured which exposed to the marine environment from 1 month to 10 months. Two features have been developed to characterise thickness variation in the corrosion layer. These features have been used to characterise corrosion progression through experimental studies. The relationship between these features and corrosion progression has been derived which is useful for corrosion progression measurement, early-stage corrosion prediction, and monitoring areas.
\end{abstract}

Keywords. Atmospheric corrosion, corrosion progression, feature extraction, laser profilometry.

\section{Introduction}

Due to its relatively low cost, mechanical strength and ease of manufacture, mild steel is the preferred metal for use in many applications. Its main disadvantage is that it corrodes easily unless adequately protected, and then rapidly loses strength, which will lead to structural failure. Corrosion is the deterioration in material properties due to interaction with the environment [1] and materials which corrode including metals and alloys, non-metals, woods, ceramics, plastics, and composites [2]. Recent studies have estimated that the direct cost of corrosion is between $3 \%$ and $4 \%$ of the gross domestic product (GDP) in every country [3]. To improve the reliability of these steel components, various non-destructive testing and evaluation (NDT\&E) methods have been adopted to detect corrosion without affecting their future performance [4-7], each of which has different capabilities.

The early stages of corrosion should be detected and evaluated, which is important in understanding the progression of corrosion, corrosion protection, lifetime extension, and condition-based maintenance. However, most studies of atmospheric corrosion using mass loss methods are used for long-term corrosion measurement and analysis.

${ }^{1}$ Corresponding Author, Hong ZHANG, Key Laboratory of Nondestructive Testing, Fuqing Branch of Fujian Normal University, Fuqing, P. R. China; E-mail: zhhgw@hotmail.com. 
Otherwise, electrochemical techniques are usually applied in laboratory investigations to understand corrosion mechanisms [8].

NDT\&E is a well-established manual testing and evaluation technique which focuses on the detection and characterisation of corrosion in steel. It has been extended to metal with corrosion. For example, acoustic emission has been used to locate pitting in steel plates [9], ultrasonic [10] and radiography [11] have been adopted to acquire and analyse images to detect corrosion, and fibre optics have been employed for the corrosion monitoring of steel in reinforced concrete [12]. Laser profilometry can provide real-time data concerning the health and operational conditions of steel components. Real corrosion is more complex, within the corrosion layer, the thickness, electrical conductivity, and magnetic permeability are changed [13], rather than being metal loss. In this paper, the thickness variation measured using laser profilometry is also used to characterise corrosion progression over exposure time.

The rest of the paper is organized as follows. Firstly, the corrosion sample design is introduced in Section II. Experimental set-up is described and feature extraction is introduced in Section III. Then, steel corrosion with different exposure times is characterised using laser profilometry in Section IV. Finally, conclusions are outlined in Section V.

\section{Sample setup}

A set of corrosion progression samples has been created to investigate the capabilities of the proposed system to differentiate between different exposure times. These samples are created by exposing S275 steel plates to marine atmospheric conditions for different lengths of time, as shown in Figure 1, giving more realistic results. Details of these samples used in experimental work are shown in Figure 3. This set of samples provides corrosion occurring after different exposure times, which are known as corrosion progression.

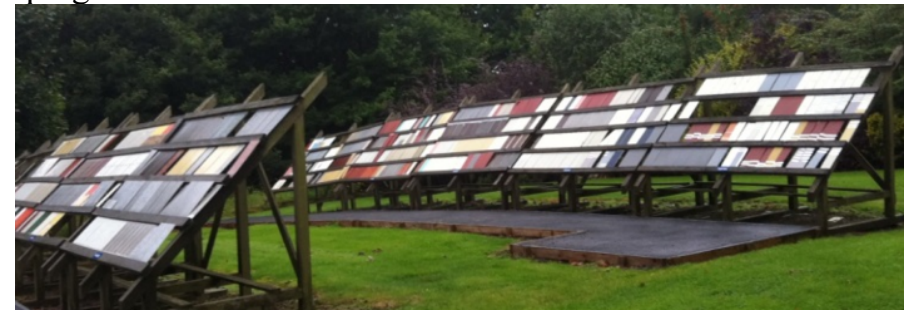

Figure 1. Sample preparation in an outdoor environment.

These samples were created by exposing a small $30 \mathrm{~mm} \times 30 \mathrm{~mm}$ section of the plates to the atmosphere for $1,3,6$, and 10 months. The differences between the stages of corrosion are evaluated to understand the progression of corrosion. Moreover, the proportions of the constituents of corrosion change over time and this has a slight effect on composition [14]. The volume of corroded metal will change because iron oxides and hydroxides have different densities. Therefore, to identify the differences among these corrosion progressions, a laser profilometry experimental system has been adopted to evaluate corrosion progression.

Laser profilometry measurements link physical property variations in steel samples to evaluate present corrosion in the material: corrosion causes a change in the 
components of steel material to iron oxides leading to an increase or decrease in thickness of the sample for different exposure times.

\section{Evaluation of corrosion progression}

To evaluate the variance in the corrosion layer with different exposure time, these samples were then measured using laser profilometry. The thickness of these steel samples is about $3 \mathrm{~mm}$, with sample (a) exposed for 1 month, sample (b) for 3 months, sample (c) for 6 months, and sample (d) for 10 months. Figure 3 shows photographs of typically corroded steel samples, showing that there is a slight increase in the thickness of the corroded area.

As shown in Figure 4, the line scans with laser profilometry for different corrosion stages results in variations in corrosion layer thickness. The lateral resolution of this machine is approximately $1 \mu \mathrm{m}$, which is depended on the size of the focused laser beam, and the resolution of the $\mathrm{Z}$-axis is about $0.01 \mu \mathrm{m}$.

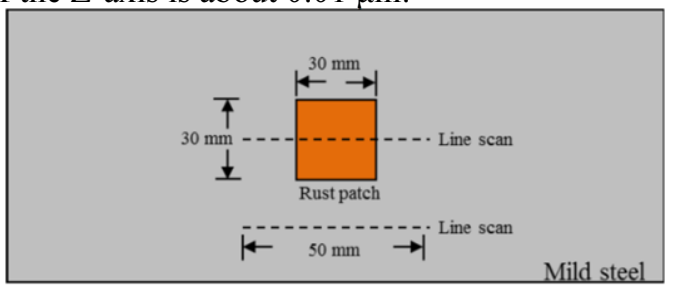

Figure 2. Line scanning position for corrosion measurement.

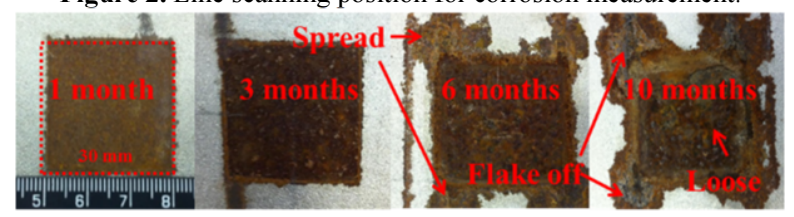

(a)

(b)

(c)

(d)

Figure 3. Photographs of corrosion with exposure times of 1, 3, 6 and 10 months.

\section{Results}

As shown in Figure 2, the line scans with laser profilometer for different corrosion stages results in variations in corrosion layer thickness. The surface measurements of corrosion samples were scanned with a laser profilometer. It is developed by the German UBM. The lateral resolution of this machine is approximately $1 \mu \mathrm{m}$, which is depended on the size of the focused laser beam, and the resolution of $Z$-axis is about $0.01 \mu \mathrm{m}$. A length of $50 \mathrm{~mm}$ line was scanned for each sample. This standard method is used for the purpose of characterising the microstructure of the four samples employed in this study. The software provided by UBM was used to calculate several parameters. The measurement results are shown in Figure 4.

It is possible to conduct non-contact and non-destructive measurements of corrosion areas with laser profilometry. The scanning length is $50 \mathrm{~mm}$, which is larger than the corrosion area. Hence, the average height is employed to denote the variance of the corrosion layer thickness for each corrosion progression. The measured average heights of corrosion for 1, 3, 6 and 10 months are $43.86 \mu \mathrm{m}, 71.72 \mu \mathrm{m}, 79.09 \mu \mathrm{m}$, and $70.99 \mu \mathrm{m}$ 
respectively. From 1 month to 6 months, the height has a positive relationship with exposure time. However, the corrosion height after 10 months shows a decrease than compared to 6 months. This is due to the nature of corrosion [15]. After 6 months exposure corrosion is spreading rather than increasing in height. Besides, the rust layer of corrosion begins to loosen and flake off. It results in the height of the 10 months corrosion sample are lower than those of 3 and 6 months. Moreover, the corrosion layer begins to decrease in mass after 6 months.

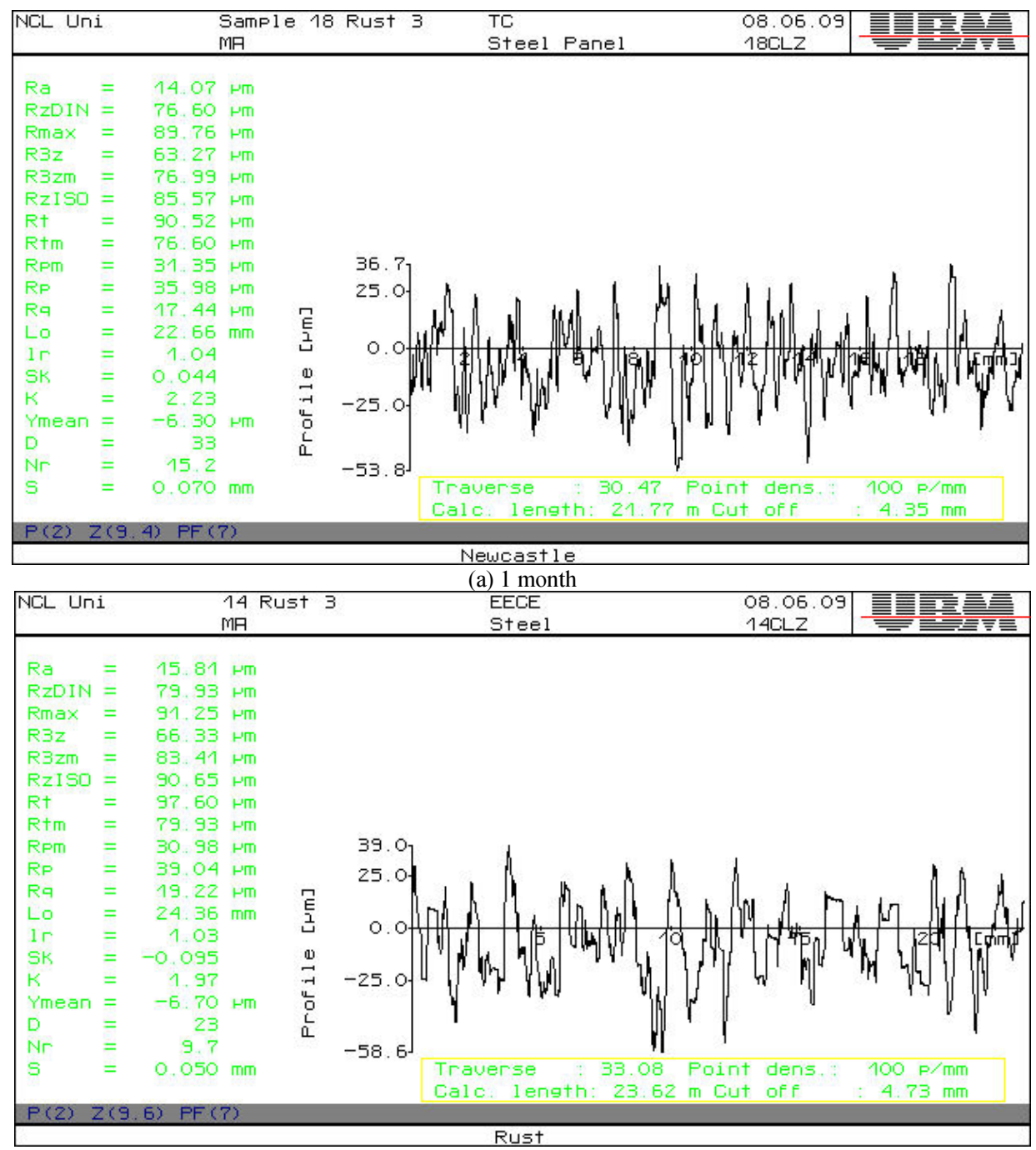

(b) 3 months 

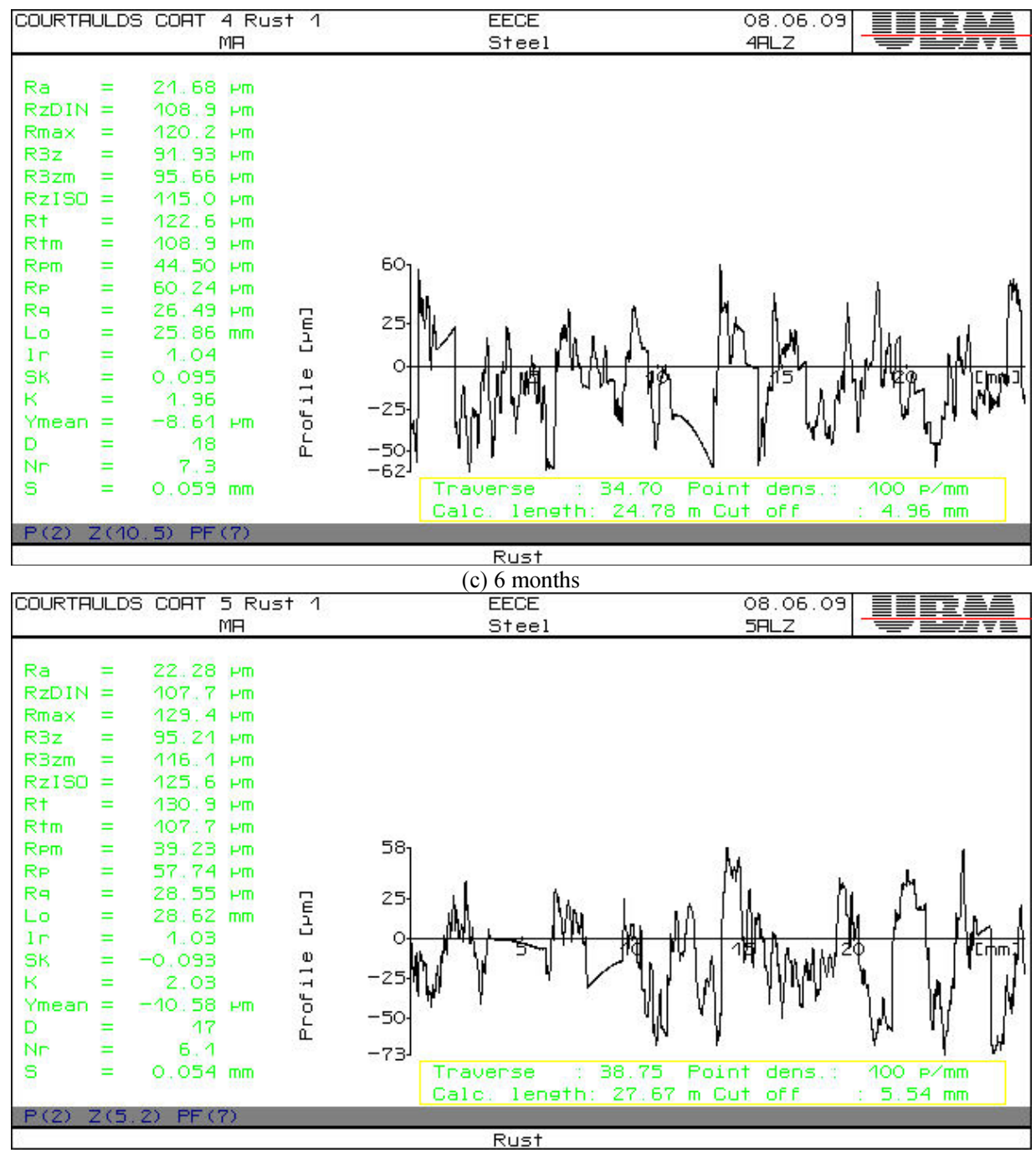

(d) 10 months

Figure 4. The surface profile of corrosion samples with different exposure times.

Because the thickness of the corrosion layer $d=d_{1}+d_{2}, d_{1}$ is the corrosion height, $d_{2}$ is corrosion depth (as shown in Figure 5). The corrosion height cannot integrally represent variance in the corrosion layer's thickness over exposure time. Furthermore, after 6 months of exposure time, the corrosion layer is going to expand. Therefore, for better understanding, the roughness value is used. 


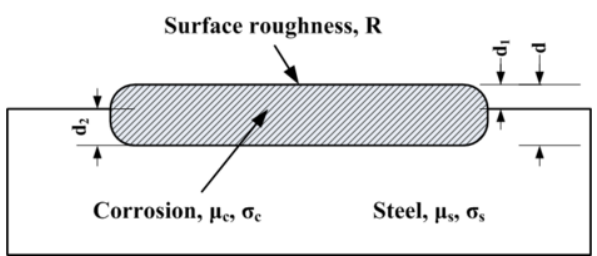

Figure 5. Model of steel and steel with corrosion.

A roughness value can be calculated either on a profile or on a surface. Many different profile parameters can be used. Roughness average $R_{a}$ is more commonly used among these profile parameters and can be calculated using equation 1:

$$
R_{a}=\frac{1}{n} \sum_{i=1}^{n}\left|y_{i}\right|
$$

where yi is the vertical distance from the mean line. For better comparison, values of $R_{a}$ are also calculated for an un-corroded steel plate. The results of the measurements of corrosion stages show that as exposure time extends from 1 month to 6 months, the thickness of the corrosion layer increases. From 6 to 10 months, the thickness of the corrosion layer increases more slowly, and then even decreases due to the loss of metal.

Table 1. $\mathrm{R}_{\mathrm{a}}$ for corrosion progression over exposure time

\begin{tabular}{ccccc}
\hline 0 month & 1 month & 3 months & 6 months & 10 months \\
\hline 14.21 & 17.44 & 19.22 & 26.49 & 28.55 \\
\hline
\end{tabular}

Table 2. Measured values for various corrosion specimens.

\begin{tabular}{|c|c|c|c|c|c|}
\hline $\begin{array}{c}\text { Exposure time } \\
\text { Parameters }\end{array}$ & $\begin{array}{c}\text { No } \\
\text { corrosion }\end{array}$ & 1 month & 3 months & 6 months & 10 months \\
\hline $\begin{array}{c}\text { Surface Roughness } \\
(\mu \mathrm{m})\end{array}$ & 14.210 & 17.440 & 19.220 & 26.490 & 28.550 \\
\hline $\begin{array}{c}\text { Conductivity } \\
\text { PV }(\Delta \text { Bnorm) (a.u.) }\end{array}$ & 0 & 0.025 & 0.034 & 0.052 & 0.056 \\
\hline $\begin{array}{c}\text { Permeability } \\
\text { Max( } \Delta \text { B }) \text { (a.u.) }\end{array}$ & 0 & -0.325 & -0.422 & -0.713 & -0.850 \\
\hline
\end{tabular}

These results from laser profilometry are shown in Table 1. Results from pulsed eddy current (PEC) [15] are shown in Table 2. The correlation coefficient of surface roughness average $R_{a}$ and electrical conductivity from the PEC results is $94.70 \% \pm$ $1.50 \%$. Moreover, the magnetic permeability and surface roughness average $R_{a}$ is $90.39 \% \pm 1.60 \%$. The results of the measurements of corrosion stages show that as exposure time extends from 1 month to 6 months, the thickness of the corrosion layer increases. From 6 to 10 months, the thickness of the corrosion layer increases more slowly, and then even decreases due to the loss of metal. 
However, laser profilometry has some advantages, due to the fact that the laser can be used without contacting the corrosion layer. Therefore variation in corrosion depth with exposure time can be evaluated in detail with real-time. Meanwhile, these results suggest that electrical conductivity and magnetic permeability are monotonically increasing with increased thickness of the corrosion layer over exposure time.

\section{Conclusions}

In this paper, laser profilometry has been employed to study the atmospheric corrosion progression over exposure time to determine variations in the physical properties of the corrosion layer. The laser profilometry is sensitive to thickness variations. It has advantage in non-contact and high resolution. Therefore, corrosion progression on mild steel can be characterised in terms of thickness. Taken together these results provide important insight into the physical change of corrosion layer over different exposure time. These results indicate an association between the properties of corrosion and corrosion progression. However, this work has some limitations, due to the fact that the laser cannot penetrate into the corrosion layer. Therefore variation in corrosion depth with exposure time is not evaluated in detail. In the further study, variations in the corrosion layer are investigated using microwave.

\section{Acknowledgement}

The work was supported by Supported by Natural Science Foundation of Fujian Province of China(2018J01787) and National Natural Science Foundation of China (61601125). Supported by Program for New Century Excellent Talents in Fujian Province University. The authors would like to thank the International Paint ${ }^{\circledR}$ for providing the experimental samples.

\section{References}

[1] Z. Ahmad, Principles of Corrosion Engineering and Corrosion Control, 2006.

[2] R. W. Revie and H. H. Uhlig, Corrosion and Corrosion Control: An Introduction to Corrosion Science and Engineering: Fourth Edition, 2008.

[3] R. Baboian, Corrosion tests and standards : application and interpretation, 2nd ed. West Conshohocken, PA: ASTM International, 2005.

[4] V. G. M. Annamdas and C. K. Soh, "Application of electromechanical impedance technique for engineering structures: Review and future issues," Journal of Intelligent Material Systems and Structures, vol. 21, pp. 41-59, 2010.

[5] P. Priyada, M. Margret, R. Ramar, et al., "Intercomparison of gamma scattering, gammatography, and radiography techniques for mild steel nonuniform corrosion detection," Review of Scientific Instruments, vol. 82, pp. 035115-035115-8, 2011

[6] P. Huthwaite, R. Ribichini, P. Cawley, et al., "Mode selection for corrosion detection in pipes and vessels via guided wave tomography," Ultrasonics, Ferroelectrics and Frequency Control, IEEE Transactions on, vol. 60, pp. 1165-1177, 2013.

[7] J. Ou and H. Li, "Structural health monitoring in mainland china: Review and future trends," Structural Health Monitoring, vol. 9, pp. 219-231, 2010.

[8] A. Nishikata, Y. Yamashita, H. Katayama, et al., "An electrochemical impedance study on atmospheric corrosion of steels in a cyclic wet-dry condition," Corrosion Science, vol. 37, pp. 2059-2069, 1995. 
[9] C. K. Lee, J. J. Scholey, S. E. Worthington, et al., "Acoustic emission from pitting corrosion in stressed stainless steel plate," Corrosion Engineering Science and Technology, vol. 43, pp. 54-63, 2008.

[10]G. Rannou, D. Thierry, and N. Le Bozec, "Ultrasonic monitoring of steel corrosion during accelerated corrosion testing and outdoor field exposures," ed, 2010.

[11]K. Edalati, N. Rastkhah, A. Kermani, et al., "The use of radiography for thickness measurement and corrosion monitoring in pipes," International Journal of Pressure Vessels and Piping, vol. 83, pp. 736$741,2006$.

[12]X. Li, S. Zhang, Z. Huang, et al., "Fiber optics sensing technique for monitoring corrosion of steel in reinforced concrete," Corrosion Science and Protection Technology, vol. 11, pp. 172-173, 1999.

[13]Y. Gotoh, H. Hirano, M. Nakano, et al., "Electromagnetic nondestructive testing of rust region in steel," IEEE Transactions on Magnetics, vol. 41, pp. 3616-3618, 2005.

[14]D. de la Fuente, I. Díaz, J. Simancas, et al., "Long-term atmospheric corrosion of mild steel," Corrosion Science, vol. 53, pp. 604-617, 2011.

[15]Y. He, G. Tian, H. Zhang, et al., "Steel Corrosion Characterization Using Pulsed Eddy Current Systems," Sensors Journal, IEEE, vol. 12, pp. 2113-2120, 2012. 